\title{
Value of Tactic Knowledge in Applied Undergraduate Education and its
}

\section{Realization}

\author{
Bo $\mathrm{Wu}$ \\ School of Economics \& Management, Chongqing Normal University, Chongqing 401331, China
}

Keywords: tactic knowledge, undergraduate education; value; realization

\begin{abstract}
Tactic knowledge was first proposed by Polanyi in his famous book Individual Knowledge. Polanyi proposed tactic knowledge because he challenged the traditional positivism that knowledge was completely objective and static. Because since the revolution of the modern science, people have used the since view and knowledge view of objectivism to treat knowledge, and think that knowledge is clear and can be expressed. With the influence of such concept of knowledge cognition, the higher education system in China has transformed the traditional education concept, so as to apply the understanding of modern education circle to tactic understanding to the higher education system of China. Based on this, this paper mainly discusses the value of tactic knowledge in the applied undergraduate education and its realization.

Compared with the traditional teaching-oriented undergraduate colleges, the applied undergraduate education emerging in China recently pays more attention to the cultivation of the students' applied skills and practical skills. Facing such new type of talent cultivation model, the traditional education concept must be changed to meet the development of applied undergraduate education in China. The concept of tactic knowledge proposed by educationalist Polanyi just meets the development trend of applied undergraduate education of China in recent years, so in the current stage, the understanding and application of tactic knowledge-related concepts is quite important to the development of education concept of applied undergraduate education. In this paper, the author will discuss the value and realization means of tactic knowledge in the applied undergraduate education according to many years' research on tactic knowledge-related theory and in combination with many years' understanding to the applied undergraduate education.
\end{abstract}

\section{Value of tactic knowledge in the applied undergraduate education}

1. Tactic knowledge can highlight the subjectivity of students as the subject of teaching

As a novel knowledge education, tactic knowledge concept is not significant in application effect in the higher education system of China, while the development of applied undergraduate education in China is relatively at the starting stage, if it is possible to explore the application of tactic knowledge-related concepts in the applied undergraduate education, the teaching quality of applied undergraduate education in China will be improved in a great extent. The most highlighted point of tactic knowledge for the applied undergraduate education is that it can fully highlight the subjectivity of students as the subject of teaching, so as to help the students fully play the master awareness in class. Only when the students can improve the learning awareness in class can the teaching quality of applied education be improved maximally. Not only in the class of applied undergraduate education, outside the class, the deep free learning concept and the characteristics of respecting the students' free thinking can make students actively learn the knowledge they are interested in, so as to achieve the purpose of cultivating practical talents in the applied undergraduate education, and this is also the maximum benefit that tactic knowledge concept plays in the applied undergraduate education.

2. Tactic knowledge can help student strengthen understanding to the knowledge learnt

Applied undergraduate education is an education model covering the widest population in the higher education system of China, with different quality of students. Many students cannot adapt to the teaching model or teaching method in the undergraduate colleges, so it is difficult for them to keep up with the course rhyme in the undergraduate education, so that the teaching quality of the 
undergraduate education is influenced. Relevant concept of tactic knowledge can help students improve the comprehension, specifically as follows: first, tactic knowledge emphasizes helping students establish an independent thinking model, but not simply asking students comprehend the knowledge learnt, so in this level, the tactic knowledge concept can help students improve the self-learning ability. Second, tactic knowledge is also helpful to improve the students' knowledge application ability. The talent cultivation objective pursued in the applied undergraduate education is to make students have full and sufficient practical ability, so as to adapt to the actual work. Therefore, the wide application of tactic knowledge in the applied undergraduate application is quite important to improve the teaching quality in the applied undergraduate education.

3. Tactic knowledge concept can help teachers enrich the class teaching mans and improve teacher-student relation

Tactic knowledge emphasizes the creation of a relaxed and free teaching atmosphere in class, while this teaching atmosphere is the objective pursued by the applied undergraduate education class. The proposer Polanyi of tactic knowledge believed that the fundamental survival soil of tactic knowledge is a free and relaxed academic atmosphere, only under such academic atmosphere can relevant teachers and students fully understand the deep-level connotation of the learning and knowledge imparting, so as to continuously improve the teaching quality of applied undergraduate education in China. The fundamental role of tactic knowledge concept in enriching the teachers' class teaching means to help teachers establish a relatively relaxed class atmosphere, and give students more spaces of free thinking, so as to achieve purpose of improving the students' self-learning ability. Besides, tactic knowledge is also beneficial to shorten the gap between the students and teachers, because of the mobility of teachers, it is difficult to establish a long-term relation between the students and teachers in the current education class, which alienates the relation between teachers and students, so as to influence the harmonious relation between teachers and students. Therefore, applying relevant concept of tactic knowledge can help to shorten the distance alienated between teachers and students to a great extent.

4. Tactic knowledge concept can help students improve learning incentive

One of the quite serious phenomena in the current applied undergraduate education is that the students do not have a strong for the learning incentive, and in class, only the teachers are worried generally, therefore, the current applied undergraduate class urgently needs the help of tactic knowledge, so as to help students understand the importance of learning. One of the important concepts of tactic knowledge is that it is thought that the class knowledge contacted by the students is just quite a small part in this knowledge system, while the real part of knowledge generally should be constructed through the students' own understanding. Therefore, tactic knowledge emphasizes the importance of students' learning incentive in a great extent, and this requires teachers to cultivate the students' own thinking ability to a certain extent and establish enough incentives to learning. Therefore, from this aspect, tactic knowledge has quite an active role. Only by continuously deeply understanding the deep connotation of tactic knowledge can the teaching objective of applied undergraduate education to reflected maximally.

\section{Application approaches of tactic knowledge understanding in the applied undergraduate education}

1. Strengthen the professional skills and quality of the frontier teachers

As the most front population applying the tactic knowledge, the frontier teachers of applied undergraduate education plays quite an important role in the development and application of tactic knowledge concept in the applied undergraduate teaching, so it is quite significant to strengthen the professional skills and quality of the frontier teachers. At present, the frontier teachers of applied undergraduate teaching in China are of various professional skills and qualities, and the teachers' occupational qualities also are inconsistent. Therefore, to increase the proportion of tactic knowledge concept in the applied undergraduate education, it is required to cultivate the professional skills and qualities of the frontier teachers. To strengthen the professional skills and qualities in the teaching of applied undergraduate education, it is required to start from the 
following: first, assess the frontier teachers according to the relevant national requirements for assessment of university teachers, for those with unsatisfactory professional for professional knowledge and skills or disqualified teaching result, it is required to train them regularly, so that they can continuously improve their skills and quality through unremitting training, so as to meet the early preparation for relevant education concepts of tactic knowledge. Second, aimed at the frontier teachers, it is also required to adopt the post system through competition, break through the traditional stable post model, so as to strengthen the circulation between posts. Meanwhile, it is required to strengthen the competition awareness of applied undergraduate teachers in mind, so as to improve the self-learning ability of frontier teachers. Only by continuously improve the professional skills and qualities of the frontier teachers can relevant teachers have the precondition to implement the tactic knowledge concept.

2. Increase the understanding of frontier teachers to tactic knowledge concept

As a relatively small teaching concept, tactic knowledge concept is not widely concerned in the education circle of China. Therefore, to really increase the application of tactic knowledge concept in the applied undergraduate teaching of China, it is required to increase the understanding of frontier teachers to tactic knowledge-related concept. The methods mainly include, first, ask relevant teachers for discussion regularly and understand the deep-level connotation of tactic knowledge by drawing the wisdoms of the masses; second, require relevant teachers to trace the understanding of international advanced peers to the tactic knowledge-related concept and continuously improve their understanding to the tactic knowledge concept by strengthening the communication wit the international peers. Only by improving the understanding to the tactic knowledge will it be able to make the concept of tactic knowledge fully applied in the teaching course of applied undergraduate education.

3. Apply heuristic class teaching model

Heuristic class teaching model is one of the most effective means fro the tactic knowledge concept, so to apply the relevant concepts of tactic knowledge in the applied undergraduate teaching of China, it is required to pay attention to the application of heuristic class teaching model. To strengthen the application of heuristic class teaching model, the following means can be used. First, tactic knowledge concept emphasizes the ability of students' self-thinking, so teachers should continuously highlight the importance of students' self-thinking ability in class teaching, guide students to think over the problems as far as possible and help students make clear the key factors in the knowledge points by beating around the bush. In this way, it is not only able to fully apply the tactic knowledge concept, but also helps to improve the students' self-thinking ability, so as to maximally conform to the cultivation concept and teaching objective of applied undergraduate education. Second, it is required to change the traditional class teaching evaluation model, pay attention to the cultivation and assessment of the students' comprehensive quality, but not only to pay attention to the students' quantitative scores. Only by continuously strengthen the application of heuristic class teaching model can the concept of heuristic knowledge be implemented in the applied undergraduate education.

4. Create a relaxed and free academic learning atmosphere

An important application approach of tactic knowledge concept is to create a relaxed and free academic learning atmosphere. The application of tactic knowledge concept can help to improve the teaching quality of applied undergraduate education in China to a great extent, so it is required to pay attention to the creation of a free academic learning atmosphere in the applied undergraduate teaching of China. The creation of a free academic learning environment can be realized through the following aspects. First, reduce the teachers' excessive time in class, give most of the class time to students, so that they can think over problems freely and establish their own thinking mode. Second, require the students to establish a class learning group, so that they can know their own shortcomings through mutual ideological communication, so as to achieve comprehensive development. Only by creating a relaxed and free academic learning environment can the students fully understand the knowledge point, so as to achieve the objective of talents cultivation and meet the teaching requirements of the society for the applied undergraduate education. 


\section{Conclusion}

As a completely new education concept, tactic knowledge concept is quite important to improve the teaching quality of applied undergraduate education in China. Therefore, the frontier teachers should continuously improve their professional skills and quality as well as relevant understanding to tactic knowledge, and incorporate the knowledge and concepts into the actual teaching in class, so as to meet the requirements of increasingly developing higher education of China. Only by continuously developing and enriching the higher education concept in China can the higher education system in China fully play its role, so as to provide talent power for the development of Chinese society and economy continuously.

\section{Acknowledgments}

This paper is one of the staged achievements of fund project of Chongqing Municipal Committee of Education Research and Route Exploration on Undergraduate Tutor System Operation Mechanism under the view of "30\% Education" (project No.: CQGJ13C262)

\section{References:}

[1] Li Suohao On Basic Property of Undergraduate Education [J] Higher Education Research

[2] Zhang Yue, Zhu Yongjiang, Connotation of Engineering Applied Undergraduate Education and its Talent Cultivation Model [J] Journal of National Academy of Education Administration, 2013, (07): 12-15.

[3] Zhong Binlin, Brief Analysis on Several Hot Issues in Undergraduate Teaching Evaluation-Discussion on New Round of System Design and Implementation Frame [J] Higher Education Research, 2011,(06):165-168.

[4] Xuan Yong, On Self-consciousness in Universities [J] Higher Education Research, 2013,(05):88-91 